\section{How Artificial Intelligence Will Change Medicine}

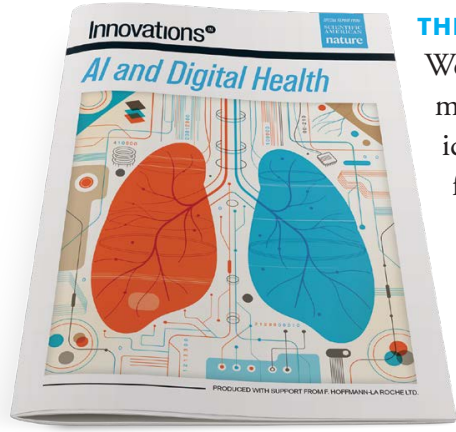

THE BIOMEDICAL WORLD IS AWASH IN DATA. We have terabytes of genomic information from mouse to human, troves of health metrics from clinical trials, and reams of so-called real-world data from insurance companies and pharmacies. Using powerful computers, scientists have scrutinized this bounty with some fine results, but it has become clear that we can learn much more with an assist from artificial intelligence. Over the next decade deep-learning neural networks will likely transform how we look for patterns in data and how research is conducted and applied to human health. This special report explores the promise of this nascent revolution.

Right now the biggest bets are being placed in the realm of drug discovery (page S49). And for good reason. The average cost of bringing a new drug to market nearly doubled between 2003 and 2013 to $\$ 2.6$ billion, and because nine out of 10 fail in the final two phases of clinical trials, most of the money goes to waste. Every large pharma company is working with at least one AI-focused start-up to see if it can raise the return on investment. Machine-learning algorithms can sift through millions of compounds, narrowing the options for a particular drug target. Perhaps more exciting, AI systems - unconstrained by prevailing theories and biases - can identify entirely new targets by spotting subtle differences at the level of tissues, cells, genes or proteins between, say, a healthy brain and one marked by Parkinson's - differences that might elude or even mystify a human scientist.

That same sharp-eyed ability is also being deployed to interpret medical scans ( page S54). Some systems can already detect early signs of cancer that might be missed by a radiologist or see things that are simply beyond human capacity — such as assessing cardiovascular risk from a retinal scan. The Food and Drug Administration is approving imaging algorithms at a rapid clip. Other AI applications lie a bit further down the road. Will the inefficiencies of today's electronic health records (EHRs) be addressed by smart systems that prevent prescribing errors and provide early warnings of disease? Some of the world's biggest tech giants are working on it (page S59).

Despite fears that machines will displace humans, most experts believe artificial and human intelligence will work synergistically. The bigger concern is a shortage of people with both biomedical knowledge and algorithm-building proficiency (page S64). If this human problem can be resolved, the key to creating successful AI applications may depend on the quality and quantity of what we feed their hungry maw. "We rely on three things," says the CEO of one deep-learning start-up. "Data, data and more data."

This report, published in Scientific American and Nature, is sponsored by F. Hoffmann-La Roche Ltd. It was produced independently by the editors of Scientific American, who take sole responsibility for the editorial content.
S49 Hunting for New Drugs with Al

The pharmaceutical industry is in a drug-discovery slump. How much can AI help? By David H. Freedman

S53 GRAPHIC:

SPEEDING UP THE SEARCH FOR DRUGS

\section{S54 Rise of Robot Radiologists}

Deep-learning algorithms are peering into MRIs and $\mathrm{x}$-rays with unmatched vision, but who is to blame when they make a mistake? By Sara Reardon

\section{S59 Can Al Fix Medical Records?}

Digitized patient charts were supposed to revolutionize medical practice. Artificial intelligence could help unlock their potential. By Cassandra Willyard

\section{S62 Wiring Minds}

Successfully applying AI to biomedicine requires innovators trained in contrasting cultures. By Amit Kaushal and Russ B. Altman

\section{EDITORIAL}

ACTING EDITOR IN CHIEF Curtis Brainard

CHIEF FEATURES EDITOR Seth Fletcher

CONTRIBUTING EDITOR Claudia Wallis

SENIOR EDITOR
Madhusree Mukerjee
SENIOR EDITOR
Jen Schwartz
SENIOR EDITOR
Kate Wong

CREATIVE DIRECTOR
Michael Mrak
SENIOR GRAPHICS EDITOR
Jen Christiansen
ASSOCIATE GRAPHICS EDITOR
Amanda Montañez

Amanda Montañez

COPY DIRECTOR
Maria-Christina Keller
SENIOR COPY EDITORS
Daniel C. Schlenoff,
Aaron Shattuck,
Angelique Rondeau

MANAGING
PRODUCTION EDITOR
Richard Hunt
PREPRESS AND
QUALITY MANAGER
Silvia De Santis

PUBLISHER AND VP Jeremy A. Abbate CORPORATE PARTNERSHIPS DIRECTOR, DIRECTOR,
NATURE RESEARCH

David Bagshaw 